\title{
Direct Passerini Reaction of Aldehydes, Isocyanides, and Aliphatic Alcohols Catalyzed by Bismuth (III) Triflate
}

\author{
Xiao-hua CAI \\ College of Chemistry and environmental Science \\ Guizhou University for Nationalites \\ Guiyang 550025, China
}

Tel: 86-851-361-0313 E-mail: caixh1111@163.com

Hui GUO

College of Pharmaceutical Sciences

Zhejiang University of Technology

Hangzhou 310014, China

E-mail: gh635@zjut.edu.cn

Bing XIE

College of Chemistry and environmental Science

Guizhou University for Nationalites

Guiyang 550025, China

Tel: 86-851-361-0313_E-mail: bing_xie1963@hotmail.com

The research is financed by the National Natural Science Foundation of China No. 20962006 and the Natural Science Foundation of the Guizhou Education Department No. 20090021

\begin{abstract}
Bismuth (III) triflate was found to be effective Lewis acid catalyst for direct alkylative Passerini reaction of aldehydes, isocyanides, and aliphatic alcohols. In the present reaction, $\alpha$-unsaturated and aromatic aldehydes used as substrates produced the corresponding $\alpha$-alkoxy amide products in good yield.
\end{abstract}

Keywords: Passerini reaction, Lewis acid catalyst, $\alpha$-alkoxy amide, Bismuth (III) triflate

\section{Introduction}

Multicomponent reactions (MCRs), due to their productivity, simple procedures, significant advantages over conventional linear-type syntheses, and facile execution, are one of the best tools in combinatorial chemistry (Zhu, J. et. al 2005, Dömling, A. et. al 2000). Therefore, the design of novel MCRs has attracted great attention from research groups working in medicinal chemistry, drug discovery, and materials science. Isocyanide-based multicomponent reactions are used extensively in target oriented and diversity oriented organic synthesis (Dömling, A., 2006). The most widely known and best characterized isocyanide-based multicomponent reaction is the Passerini three-component reaction (P-3CR). In the Passerini 3CR, an isocyanide, a carboxylic acid, and either an aldehyde or a ketone react with one another to yield an $\alpha$-acyloxycarboxamide (Dömling, A. et. al 2006). But the use of phenol or aliphatic alcohol derivatives instead of a carboxylic acid component has not been realized until recently. O-arylative Passerini-type reaction (El Kaim, L. et. al 2006, El Kaim, L. et. al 2007) was reported by the using $O$-nitrophenol derivatives in 2006, which have a more acidic proton compared to aliphatic alcohols. On the other hand, Chatani and co-workers (Tobisu, M. et. al 2007, Yoshioka, S. at. al 2005) reported that the reaction of benzaldehyde, isocyanide, and silyl-protected aliphatic alcohol can be catalyzed by triflic acid to give $\alpha$-alkoxy amides in moderate yield. But the direct Passerini reaction using aliphatic alcohol derivatives instead of carboxylic acid components are still unsolved and the corresponding researches are less found. Yanai group have reported that direct alkylative Passerini reaction of aldehydes, isocyanides, and free aliphatic alcohols catalyzed by Indium triflate 
(Yanai, H. et. al 2009). Therefore, the development of direct Passerini three-component type reaction of aldehydes, isocyanides, and aliphatic alcohols is still very necessary.

Bismuth (III) triflate is known as mild, soft, chemically stable Lewis acid, and used widely for condensation (Matsushita, Y. et. al 2005, Yadav, J. S. et. al 2006), addition (Ollevier, T. et. al 2009, Ollevier, T. et. al 2007), rearrangement (Ollevier, T. et. al 2006, Ollevier, T. et. al 2008) and multicomponent reactions (Ollevier, T. et. al 2003, Ollevier, T. 2006) as an effective catalyst in organic synthesis. In the present study, we were interested in the application of bismuth (III) triflate Lewis acid to the direct P-3CR of aldehydes, isocyanides, and aliphatic alcohols at reflux in THF providing to the corresponding $\alpha$-alkoxy amide products (Figure 1).

To explore the effective Bismuth (III) triflate for direct O-alkylative P-3CR reaction and optimize the reaction condition, our initial attempts to examine the reaction of benzaldehyde, tert-butyl isocyanide and 2-propanol in THF with $\mathrm{Bi}(\mathrm{OTf})_{3}$ as catalyst. In the presence of $20 \mathrm{~mol} \% \mathrm{Bi}(\mathrm{OTf})_{3}$, the reaction of benzaldehyde with 1.0 molar equiv of tert-butyl isocyanide and 2-propanol at reflux for $10 \mathrm{~h}$ gave alkylative Passerini product in $40 \%$ yield, and the product yield improved to $53 \%$ when tert-butyl isocyanide was added to 2.0 molar equiv. Moreover, the stepwise addition of tert-butyl isocyanide in reaction mixture dramatically increased the product yield. For example, in the presence of $20 \mathrm{~mol} \%$ of $\mathrm{Bi}(\mathrm{OTf})_{3}$, benzaldehyde was reacted with 1.0 molar equiv of tert-butyl isocyanide at reflux for $10 \mathrm{~h}$, then further treatment by additional 1.0 molar equiv of tert-butylisocyanide in THF gave the corresponding product at reflux for $10 \mathrm{~h}$ in $75 \%$ yield.

Secondly, we checked the reaction with various aldehydes under the optimized conditions, the results exhibited the reactions with aromatic or $\alpha, \beta$-unsaturated aldehydes to give alkylative Passerini product in good yield, such as, the reaction of cinnamaldehyde, tert-butyl isocyanide, and 2-propanol was nicely catalyzed by $20 \mathrm{~mol} \%$ of $\mathrm{Bi}(\mathrm{OTf})_{3}$ to give the corresponding $\alpha$-isopropoxy alkylative amides $10 \mathrm{~h}$ in $82 \%$ yield. Under the same conditions, 2-naphthaldehyde and 2-furaldehyde gave Passerini products $\mathbf{4 g}$ and $\mathbf{4 h}$ in 73 and $78 \%$ yield, respectively. Unfortunately, with aliphatic aldehydes, the yield of O-alkylated products was not so good. For example, the reaction of cyclopentylaldehyde, $n$-propylaldehyde with tert-butyl isocyanide and 2-propanol, and produced the desired product $4 \mathbf{i}$ and $\mathbf{4 j}$ only in $50 \%$ and $44 \%$ yield.

Finally, we examined the reaction with various alcohols instead of 2-propanol, and this reaction also proceeded in secondary or primary alcohol. Under the same conditions, the reaction in cyclopentanol and cyclohexanol gave $\mathbf{4 k}$ and $4 \mathrm{I}$ in $72 \%$ and $67 \%$ yield, respectively. In general, the reactivity of primary alcohol such as $n$-butanol (4m) and $n$-propanol (4n) was lower than that of several secondary alcohols.

\section{Experimental}

In a typical procedure, a mixture of $\mathrm{Bi}(\mathrm{OTf})_{3}(0.4 \mathrm{mmol}, 20 \mathrm{~mol} \%)$, aliphatic alcohol $(2.0 \mathrm{mmol})$ in THF (30 ml), $t$-BuNC (2.0 mmol, 1.0 equiv) and aldehyde $(2.0 \mathrm{mmol})$ were added. After being stirred at reflux for $10 \mathrm{~h}$, the reaction mixture was treated by additional $t$-BuNC $(2.0 \mathrm{mmol}, 1.0$ equiv) in THF $(20 \mathrm{ml})$, and then stirred at reflux for $10 \mathrm{~h}$. The resultant mixture was concentrated under reduced pressure and purified by column chromatography on silica gel and gave the corresponding direct alkylative Passerini products.

$\mathrm{N}$-tert-Butyl-2-isopropoxy-2-phenylacetamide (4a) as a white crystal. Mp. $58.5 \sim 60.0{ }^{\circ} \mathrm{C}\left(57.5 \sim 59.0{ }^{\circ} \mathrm{C}^{[8]}\right) ;{ }^{1} \mathrm{H} \mathrm{NMR}$ $\left(400 \mathrm{MHz}, \mathrm{CDCl}_{3}\right) \delta 1.07(3 \mathrm{H}, \mathrm{d}, \mathrm{J}=6.2 \mathrm{~Hz}), 1.16(3 \mathrm{H}, \mathrm{d}, \mathrm{J}=6.2 \mathrm{~Hz}), 1.29(9 \mathrm{H}, \mathrm{s}), 3.61(1 \mathrm{H}, \mathrm{J}=6.1 \mathrm{~Hz}), 4.59(1 \mathrm{H}$, s), $6.62(1 \mathrm{H}$, brs, $-\mathrm{NH}), 7.18-7.30(3 \mathrm{H}, \mathrm{m}), 7.33-7.38(2 \mathrm{H}, \mathrm{m}) ;{ }^{13} \mathrm{C} \mathrm{NMR}\left(100 \mathrm{MHz}, \mathrm{CDCl}_{3}\right) \delta 22.3$ and 22.9, 29.6, 51.3, 72.0, 81.1, 125.9, 127.4, 127.8, 139.1, 171.2; ESI-MS m/z 272([M+Na $\left.]^{+}, 100 \%\right)$; Anal. Calcd for $\mathrm{C}_{15} \mathrm{H}_{23} \mathrm{NO}_{2}$ : C, 72.26; H, 9.29; N, 5.63. Found: C, 72.29; H, 9.20; N, 5.58.

N-tert-Butyl-2-(2-furyl)-2-isopropoxyacetamide (4h) ${ }^{1} \mathrm{H}$ NMR (400 MHz, $\left.\mathrm{CDCl}_{3}\right) \delta 1.18(3 \mathrm{H}, \mathrm{d}, \mathrm{J}=6.2 \mathrm{~Hz}), 1.23$ $(3 \mathrm{H}, \mathrm{d}, \mathrm{J}=6.2 \mathrm{~Hz}), 1.42(9 \mathrm{H}, \mathrm{s}), 3.72(1 \mathrm{H}, \mathrm{J}=6.2 \mathrm{~Hz}), 4.75(1 \mathrm{H}, \mathrm{s}), 6.28-6.34(2 \mathrm{H}, \mathrm{m}), 6.68(1 \mathrm{H}, \mathrm{brs}, \mathrm{NH})$, 7.33-7.37 (1H, m); ${ }^{13} \mathrm{C}$ NMR $\left(100 \mathrm{MHz}, \mathrm{CDCl}_{3}\right) \delta 22.1,22.8,29.2,51.8,72.0,73.8,110.1,110.8,143.2,151.8$, 169.0; ESI-MS m/z: $262\left([\mathrm{M}+\mathrm{H}]^{+}, 100 \%\right)$; Anal. Calcd for $\mathrm{C}_{13} \mathrm{H}_{21} \mathrm{NO}_{3}: \mathrm{C}, 65.26 ; \mathrm{H}, 8.85 ; \mathrm{N}, 5.86$. Found: $\mathrm{C}, 65.12$; $\mathrm{H}, 8.91 ; \mathrm{N}, 5.96$.

\section{Conclusion}

In conclusion, we have developed a new and efficient method for the direct Passerini alkylative reaction of aldehydes, isocyanides, and aliphatic alcohols using aliphatic alcohols instead of a carboxylic acid component. In the present reaction, $\alpha$-unsaturated and aromatic aldehydes used as nice substrates produced the corresponding $\alpha$-alkoxy amide products in good yield. The present reaction is a highly useful method to construct the chemical library of $\alpha$-alkoxy amide derivatives. 


\section{References}

Dömling, A. (2006). Recent developments in isocyanide based multicomponent reactions in applied chemistry, Chem. Rev., 106: 17-89.

Dömling, A., Ugi, I. (2000). Multicomponent reactions with isocyanides, Angew. Chem. Int. Ed., 39: 3168-3210.

El Kaim, L., Gizolme, M., Grimaud, L. (2006). O-Arylative passerini reactions, Org. Lett., 8: 5021-5023.

El Kaim, L., Gizolme, M., Grimaud, L., Oble, J. (2007). Smiles rearrangements in Ugi- and Passerini-type couplings: New multicomponent access to O- and N-arylamides, J. Org. Chem., 72: 4169-4180.

Matsushita, Y., Sugamoto, K., Matsui, T. (2005). Bismuth triflate catalyzed mukaiyama aldol reaction in an ionic liquid, Eur. J. Org. Chem., 4971-4973.

Ollevier, T., Ba, T. Y. (2003). Highly efficient three-component synthesis of protected homoallylic amines by bismuth triflate-catalyzed allylation of aldimines, Tetrahedron Lett., 44: 9003-9005.

Ollevier, T., Etienne, N. (2006). synthesis of $\beta$-amino esters by bismuth triflate catalyzed three-component Mannich-type reaction, Synlett, 219-222.

Ollevier, T., Li, Z. Y. (2007). Bismuth triflate catalyzed cllylation of cldehydes with cllylstannane under microwave assistance, Eur. J. Org. Chem., 34: 5665-5668.

Ollevier, T., Li, Z. Y. (2009). Bismuth triflate-catalyzed addition of allylsilanes to N-alkoxycarbonyl- amino sulfones: Convenient access to 3-Cbz-protected cyclohexenylamines, Adv. Synth. Cat., 351: 3251-3259.

Ollevier, T., Mwene-Mbeja, T. M. (2006). Bismuth triflate catalyzed Claisen rearrangement of allyl naphthyl ethers, Tetrahedron Lett., 47: 4051-4055.

Ollevier, T., Mwene-Mbeja, T. M. (2008). Bismuth triflate-catalyzed rearrangement of acetates of the Baylis-Hillman adducts into (E)-trisubstituted alkenes, Tetrahedron, 64: 5150-5155.

Tobisu, M., Kitajima, A., Yoshioka, S., Hyodo, I., Oshita, M., Chatani, N. (2007). Brønsted acid catalyzed formal insertion of isocyanides into a C-O bond of acetals. J. Am. Chem. Soc., 129: 11431-11437.

Yadav, J. S., SubbaReddy, B. V., Gayathri, K. U., Meraj, S., Prasad, A, R. (2006). Bismuth(III) triflate catalyzed condensation of Isatin with indoles and pyrroles: A facile synthesis of 3,3-diindolyl- and 3,3-dipyrrolyl oxindoles, Synthesis, 4121-4123.

Yanai, H; Oguchi, T. and Taguchi, T. (2009). Direct alkylative passerini reaction of aldehydes, isocyanides, and free aliphatic alcohols catalyzed by indium (III) triflate, J. Org. Chem. , 74: 3927-3929.

Yoshioka, S., Oshita, M., Tobisu, M.; Chatani, N. (2005). $\mathrm{GaCl}_{3}$-catalyzed insertion of isocyanides into a $\mathrm{C}-\mathrm{O}$ bond in byclic ketals and acetals. Org. Lett., 7, 3697-3699

Zhu, J., Bienaymë, H. (2005). Multicomponent Reactions, Wiley-VCH: Weinheim, Germany. 
Table 1. P-3CR of Aldehydes, Isocyanides, and Aliphatic Alcohols Catalyzed by Bi(OTf $)_{3}$

\begin{tabular}{cccc}
\hline Product $^{a}$ & $R_{1}$ & $R_{2}$ & ${\text { Yield }(\%)^{b}}^{b}$ \\
\hline $\mathbf{4 a}$ & $\mathrm{Ph}$ & $i$-Pr & 75 \\
$\mathbf{4 b}$ & $p$-MeOPh & $i$-Pr & 69 \\
$\mathbf{4 c}$ & $p-\mathrm{BrPh}$ & $i$-Pr & 76 \\
$\mathbf{4 d}$ & $p$-MePh & $i$-Pr & 72 \\
$\mathbf{4 e}$ & propenyl & $i$-Pr & 78 \\
$\mathbf{4 f}$ & styryl & $i$-Pr & 82 \\
$\mathbf{4 g}$ & 2 -naphthyl & $i$-Pr & 73 \\
$\mathbf{4 h}$ & 2 -furyl & $i$-Pr & 78 \\
$\mathbf{4 i}$ & cyclopentyl & $i$-Pr & 50 \\
$\mathbf{4 j}$ & $n$-propyl & $i$-Pr & 44 \\
$\mathbf{4 k}$ & $\mathrm{Ph}$ & cyclopentyl & 72 \\
$\mathbf{4 l}$ & $\mathrm{Ph}$ & cyclohexyl & 67 \\
$\mathbf{4 m}$ & $\mathrm{Ph}$ & $n$-butyl & 38 \\
$\mathbf{4 n}$ & $\mathrm{Ph}$ & $n$-propyl & 32 \\
\hline
\end{tabular}

${ }^{\mathrm{a}}$ All known compounds were characterized by comparing their spectral data with those reported; ${ }^{\mathrm{b}}$ Isolated yields

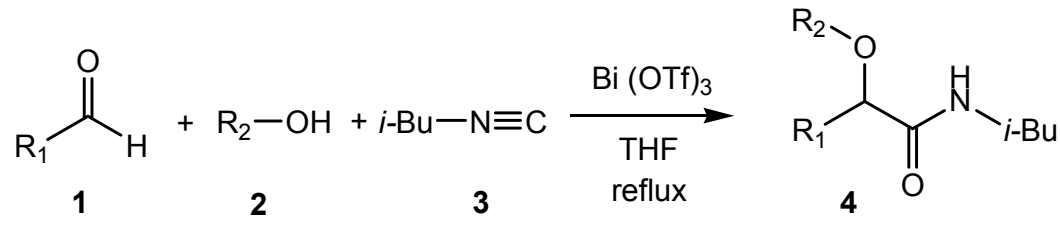

Figure 1. P-3CR of Aldehydes, Isocyanides, and Aliphatic Alcohols Catalyzed by Bi(OTf $)_{3}$ 